\title{
Bispectral index monitoring during total intravenous anaesthesia: A comparative study between two dosage regimes of propofol
}

\author{
B Sanjeev Kumar ${ }^{1}$, Pratheeba $\mathbf{N}^{2, *}$, Remadevi $\mathbf{R}^{3}$, Ravindra Bhat $\mathbf{R}^{4}$, Senthilnathan $\mathbf{M}^{5}$ \\ 1,3,5Assistant Professor, ${ }^{2,4}$ Associate Professor, Dept. of Anaesthesiology, Indira Gandhi Medical College and Research Institute, \\ Puducherry, India
}

*Corresponding Author:

Email: pratheeba.rk@gmail.com

Received: $12^{\text {th }}$ December, 2017

Accepted: $17^{\text {th }}$ February 2018

\begin{abstract}
Introduction: The potential long-term complication of intraoperative awareness needs to be addressed. These complications range from mild auditory perceptions to being fully awake. Studies with prospective patient interviews that specifically inquire about awareness have noted an incidence of 0.1 to 0.2 percent in the general population and approximately 1 percent in high-risk populations.

Aims and Objectives: Comparative evaluation of two dose regimens of propofol to assess the depth of anesthesia during total intravenous anesthesia using Bispectral index monitor. The objectives were to find the average Bispectral index during propofol anaesthesia, compare and determine, in two groups, the amount of additional bolus or reduction in the infusion rates of propofol in two dose regimens and to correlate the Bispectral indices with hemodynamic monitoring and to assess incidence of postoperative awareness in the two groups.

Materials and Methods: This study was conducted as a prospective randomized double-blind study in a teaching hospital. After the approval from the Ethics committee of the institution, 50 ASA I-II patients were randomly divided into two groups (GI and GII). The patients were induced with a standard regimen of $2 \mathrm{mg} \mathrm{kg}^{-1}$ of propofol and $0.1 \mathrm{mg} \mathrm{kg}^{-1}$ of vecuronium and intubated using appropriate sized endotracheal tube. Following intubation, propofol was infused according to the group the patients was allotted. GI received propofol infusion maintenance dose of $10 \mathrm{mg} \mathrm{kg}^{-1}$ hour for the first 10 minutes following intubation, $8 \mathrm{mg}$ $\mathrm{kg}^{-1}$ hour for the next 10 minutes and thereafter $6 \mathrm{mg} \mathrm{kg}^{-1}$ hour for the entire length of the surgery. GII received propofol infusion maintenance dose of $8 \mathrm{mg} \mathrm{kg}^{-1}$ hour for the first 10 minutes following intubation, $6 \mathrm{mg} \mathrm{kg}{ }^{-1}$ hour for the next 10 minutes and thereafter $4 \mathrm{mg} \mathrm{kg}^{-1}$ hour for the entire length of the surgery. The Bispectral index, blood pressure and heart rate were monitored during intubation and thereafter every five minutes for the entire length of the surgery. And the propofol dose was adjusted to maintain the Bispectral index between 40 and 60 .

Results: Additional doses of propofol were required in the GII 8/6/4 mg kg-1 hour regimen when compared to GI 10/8/6 mg kg-1 hour dose regimen. The average Bispectral index was comparable in the two groups.

Conclusion: Patients were hemodynamically stable when the Bispectral index was maintained between 40 and 60 . Intraoperative awareness was not detected during this study.
\end{abstract}

Keywords: Propofol, Bispectral index, Intraoperative awareness.

\section{Introduction}

The potential long-term complication of intraoperative awareness needs to be addressed. These complications range from mild auditory perceptions to being fully awake. Studies with prospective patient interviews that specifically inquire about awareness have noted an incidence of 0.1 to 0.2 percent in the general population and approximately 1 percent in high-risk populations. $^{1-4}$

Therefore, patients undergoing surgery under general anesthesia require an adequate level or hypnosis to protect them from stress of awareness and recall of traumatic interventions. Conventionally, the hypnotic state is assessed by observing changes in the respiratory and cardiovascular system. However, in recent times, the hypnotic state is assessed by monitoring the electrical activity of the brain which directly indicates the depth of anesthesia. This has been made possible by the introduction of newer and more sophisticated delivery system for total intravenous anesthesia (TIVA) and the Bispectral index monitor, which allows a computed analysis of real time EEG to assess the depth of anesthesia continuously.

In this study, we have analyzed two dosage regimens of continuous propofol infusion in two group to assess the depth of anesthesia using Bispectral index for the entire length of surgery performed.

\section{Materials and Methods}

After the approval from the institute's ethics committee (PIMS/Ethics/2008-32), A pilot study was conducted to determine the sample size. The mean \pm standard dose of propofol in the study group GII was $680.21 \pm 120.32$ whereas in the control group GI. (GI received propofol infusion maintenance dose of $10 \mathrm{mg}$ $\mathrm{kg}^{-1}$ hour for the first 10 minutes following intubation, 8 $\mathrm{mg} \mathrm{kg}^{-1}$ hour for the next 10 minutes and thereafter $6 \mathrm{mg}$ $\mathrm{kg}^{-1}$ hour for the entire length of the surgery) it was $616.121 \pm 104.73$. Considering $95 \%$ confidence interval and $80 \%$ power the estimated sample size was 49 in each group which was rounded of to 50. Fifty ASA I and II patients, with ages ranging from 18 to 50 years and who 
underwent elective surgical procedures lasting less than two hours were randomly divided into two groups (GI and GII). A Patients with head injuries, epilepsy, intracranial tumors, hydrocephalus, cardiovascular disease, peripheral vascular disease those on antipsychotic drugs and those who underwent laparoscopic procedures were excluded from the study.

All the patients enrolled for the study were premedicated with injection glycopyrrolate $0.2 \mathrm{mg}$ intravenously. Two peripheral intravenous lines (18G) were secured on either hand, one dedicated line for propofol infusion and other one, with a 3-way connector for vecuronium and fentanyl maintenance infusions. Perfusor ${ }^{\circledR}$ compact S, B. Braun Melsungen AG infusion pumps were used for the study. These patients were induced with propofol $2 \mathrm{mg} \mathrm{kg}^{-1}$, injection Fentanyl $2 \mu \mathrm{g}$ $\mathrm{kg}^{-1}$, isoflurane (minimum alveolar concentration 1.2), and using vecuronium $0.1 \mathrm{mg} \mathrm{kg}^{-1}$ patients were intubated using appropriate-sized endotracheal tube. (No regional anaesthetic was supplemented in any of the groups). Following intubation, propofol was infused according to the group the patients was allotted. GI received propofol

infusion maintenance dose of $10 \mathrm{mg} \mathrm{kg}^{-1}$ hour for the first 10 minutes following intubation, $8 \mathrm{mg} \mathrm{kg}^{-1}$ hour for the next 10 minutes and thereafter $6 \mathrm{mg} \mathrm{kg}^{-1}$ hour for the entire length of the surgery. GII received propofol infusion maintenance dose of $8 \mathrm{mg} \mathrm{kg}^{-1}$ hour for the first 10 minutes following intubation, $6 \mathrm{mg} \mathrm{kg}^{-1}$ hour for the next 10 minutes and thereafter $4 \mathrm{mg} \mathrm{kg}^{-1}$ hour for the entire length of the surgery. Vecuronium $0.8 \mu \mathrm{g} \mathrm{kg}-1 \mathrm{~min}$ and fentanyl $1 \mu \mathrm{g} \mathrm{kg}^{-1}$ hour infusion was started after the bolus dose of propofol, during the maintenance phase anaesthesia.

The Bispectral index, was monitored using BIS VIEW $^{\mathrm{TM}}$ Aspect Medical Systems, U.S.A. Blood pressure and heart rate were monitored during intubation and thereafter every five minutes for the entire length of the surgery. The propofol infusion dose was increased or decreased by $0.5 \mu \mathrm{g} \mathrm{ml}^{-1}$ to achieve a predetermined Bispectral index value of 40-60 to maintain general anaesthesia. At the end of the surgery, propofol (GI and GII), vecuronium $0.8 \mu \mathrm{g} \mathrm{kg}^{-1}$ min and fentanyl $1 \mu \mathrm{g} \mathrm{kg}$ ${ }^{1}$ hour infusion rates were stopped and neuromuscular blockade reversed using neostigmine and glycopyrrolate. After 12 hours following extubation, the patients were questioned to find if they were aware of any pain or can recall any event during the intraoperative period. An anaesthetist who was not involved in the conduct of anaesthesia asked the following questions to the patient.

1. Did you try to alert anyone during surgery?5

2. Do you have any recall while surgery was being done?

3. Do you have any unpleasant dream about your surgery or operating room?

\section{Statistical Analysis}

All data were recorded in Microsoft excel chart, and statistical analysis was done by Statistical Package for Social Sciences (SPSS Statistics for Windows, Version 17.0. SPSS Inc., Chicago). Hemodynamic data [heart rate (HR), systolic blood pressure (SBP) and diastolic blood pressure (DBP)] was expressed as mean \pm standard deviation. Hemodynamic data were analyzed using repeated measures of ANOVA. The Bispectral index and additional changes in propofol doses were compared in the two groups of patients using unpaired $\mathrm{t}$ test.

\section{Results}

The following observations were made after studying 50 patients belonging to two groups (GI and GII). The demographic profile in both the groups was comparable in terms of mean age, sex, weight and duration of anaesthesia. (Table 1). The distribution of the types of surgeries in both the groups were comparable. (Fig. 1)

Induction of anesthesia was rapid and smooth without any cough, laryngospasm or any involuntary movement. The mean doses (induction and maintenance) of propofol administered to both groups are listed in Table 2. GI received an average dose of $686.1 \pm 124.5$ $\mathrm{mg}$ and GII received $562.7 \pm 94.9 \mathrm{mg}$. The BIS values were maintained between 40 and 60 in both groups. The mean BIS values were comparable between the two groups with $\mathrm{p}=0.519$. (Table 3 )

During the procedure, the mean systolic and diastolic blood pressure and heart rates showed similar patterns in the two groups. (Table 4, Fig. 2). No unacceptable hypotension or hypertension occurred in any patient.

Patients in GII received additional bolus doses of 20 $\mathrm{mg}$ aliquots of propofol during the maintenance of anesthesia in comparison to GI $\mathrm{p}<0.001$ (Table 5 and Fig. 3). Awareness did not occur in any patient. All patients reported total amnesia for the intraoperative period and were satisfied with this kind of anesthesia.

Table 1: Patient characteristics

\begin{tabular}{|l|c|c|}
\hline \multirow{2}{*}{$\begin{array}{c}\text { Groups Age } \\
(\text { mean } \pm \text { SD) years }\end{array}$} & Group I & Group II \\
\cline { 2 - 3 } & $33.4 \pm 9.8$ & $32.3 \pm 9.8$ \\
\hline Male & 14 & 15 \\
\hline Female & 11 & 10 \\
\hline Weight $(\mathrm{kg})$ & $54.4 \pm 7.1$ & $55.2 \pm 8.5$ \\
\hline $\begin{array}{l}\text { Duration of } \\
\text { anaesthesia }\end{array}$ & $76.4 \pm 17.8$ & $83.2 \pm 15.2$ \\
\hline
\end{tabular}


Table 2: Total propofol dose in the two groups

\begin{tabular}{|l|c|c|}
\hline \multicolumn{1}{|c|}{ Group } & Group I & Group II \\
\hline $\begin{array}{l}\text { Total propofol } \\
\text { dose }\end{array}$ & $686.1 \pm 124.5$ & $562.7 \pm 94.9$ \\
\hline
\end{tabular}

Table 3: Bispectral index in the two groups

\begin{tabular}{|l|c|c|}
\hline \multicolumn{1}{|c|}{ Group } & Group I & Group II \\
\hline $\begin{array}{l}\text { Bispectral index } \\
(\text { mean } \pm \text { SD) }\end{array}$ & $49.1 \pm 2^{*}$ & $48.7 \pm 1.9$ \\
\hline $\begin{array}{l}\text { Bispectral index } \\
\text { (minimum) }\end{array}$ & 38 & 38 \\
\hline $\begin{array}{l}\text { Bispectral index } \\
\text { (maximum) }\end{array}$ & 59 & 59 \\
\hline
\end{tabular}

* Bispectral index (mean \pm SD) $p=0.519$
Table 4: Cardiovascular variables in the two groups

\begin{tabular}{|l|c|c|}
\hline Groups & Group I & Group II \\
\hline Heart rate (mean \pm SD) & $71.99 \pm 4.4$ & $73.35 \pm 6.4$ \\
\hline $\begin{array}{l}\text { Systolic blood pressure } \\
(\text { mean } \pm \text { SD) }\end{array}$ & $110.4 \pm 3.8$ & $112.1 \pm 3.6$ \\
\hline $\begin{array}{l}\text { Diastolic blood } \\
\text { pressure (mean } \pm \text { SD) }\end{array}$ & $72.5 \pm 2$ & $73.9 \pm 3.3$ \\
\hline
\end{tabular}

Table 5: Additional propofol dose in the two groups

\begin{tabular}{|c|c|c|}
\hline Groups & Group I & Group II \\
\hline $\begin{array}{l}\text { Additional dose } \\
\text { required }(\text { mean } \pm S D) \mathrm{mg}\end{array}$ & $5.6 \pm 9.2^{* *}$ & $21.6 \pm 9.9$ \\
\hline
\end{tabular}

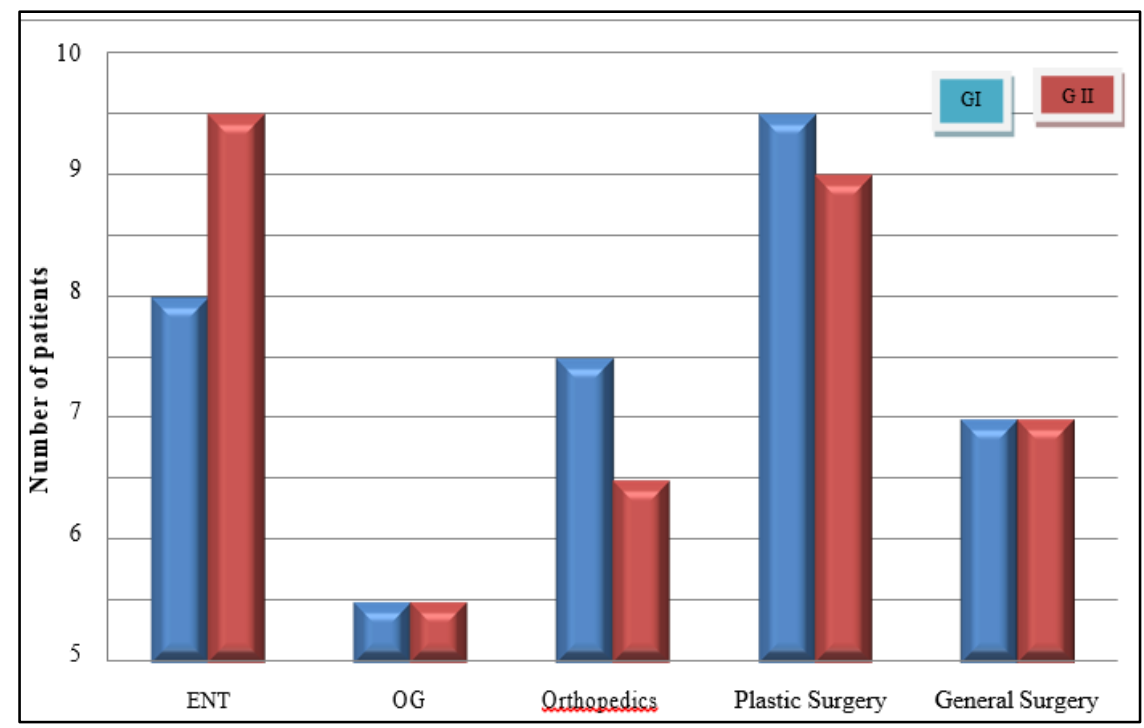

Fig. 1: Distribution of the types of surgery in the two groups

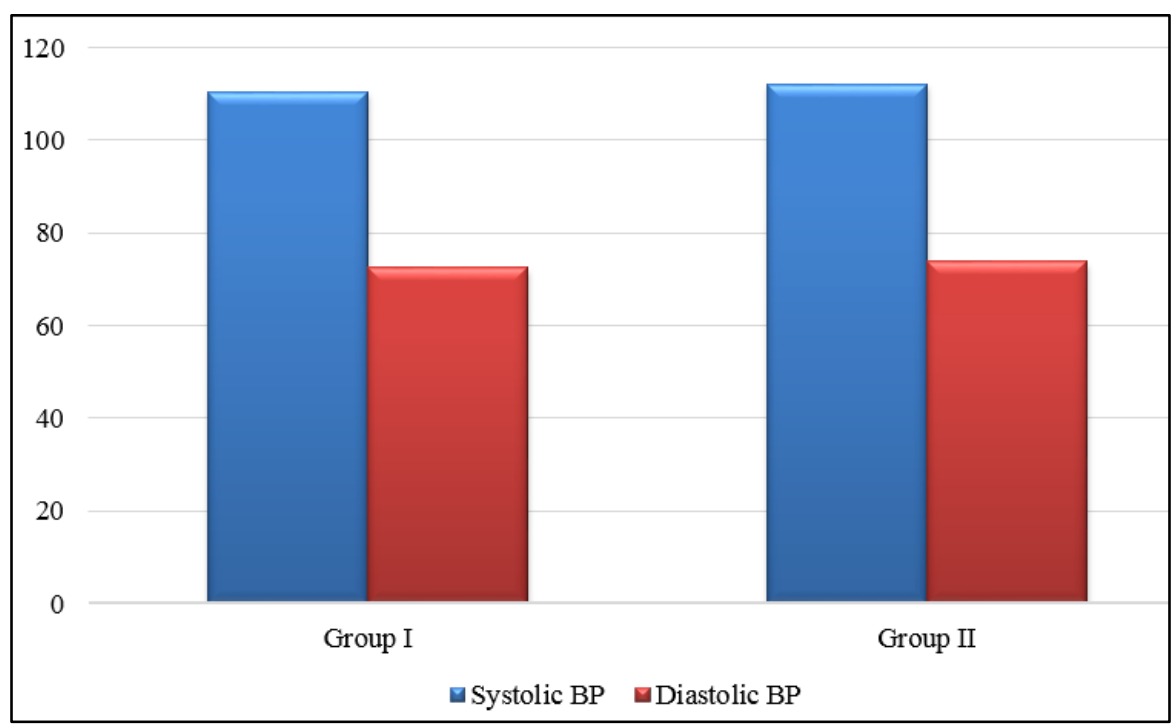

Fig. 2: Systolic and diastolic blood pressure in the two groups 


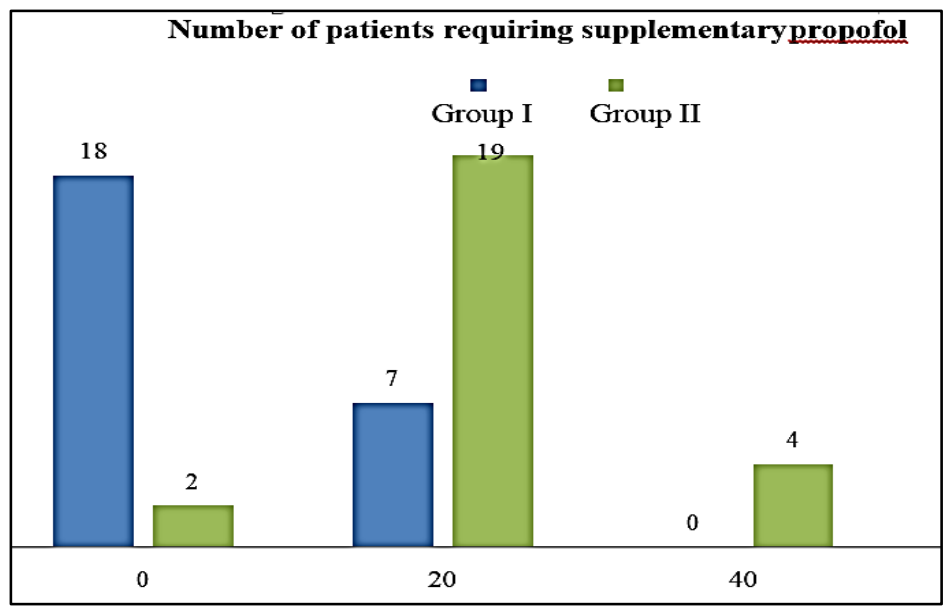

Fig. 3: Bar chart showing number of patients requiring supplementary doses in the two groups

\section{Discussion}

The introduction of TIVA along with newer sophisticated delivery systems has made control of intravenous anesthesia straightforward and user friendly. It has several advantages over inhalational agents namely quick induction and recovery, no operating room pollution, easy titrability, decreased postoperative nausea and vomiting. The infusion rate can be titrated according to changes in the vital signs, depth of anesthesia and surgical stimuli. The requirement of hypnosis and analgesia can be individualized. ${ }^{6}$ One of the disadvantages of TIVA is the absence of reliable technique for monitoring the plasma concentration which is an indicator of the depth of anesthesia. The Bispectral index monitor is a reliable source to monitor the depth of anesthesia as it can easily be interpreted and can be related best to the actual level of sedation. It also allows titration of the drug to specific needs of the patient and enables increased speed of return of consciousness and recovery. ${ }^{7}$ In this study, we compared two step-down dose regimes of propofol (GI: 10/8/6 $\mathrm{mg} \mathrm{kg}{ }^{-1}$ hour and GII: $8 / 6 / 4 \mathrm{mg} \mathrm{kg}^{-1}$ hour) following an induction dose of propofol $\left(2 \mathrm{mg} \mathrm{kg}^{-1}\right)$ using BIS monitoring with concurrent hemodynamic measurements. A fixed rate fentanyl infusion of $1 \mu \mathrm{g} \mathrm{kg}^{-1}$ hour was given. BIS value was maintained between 40 and 60 . The only difference between the two groups was the number of additional doses of propofol that was given when the BIS value approached 60 .

The dosage of propofol is based on a 3 compartmental model of propofol pharmacokinetics. After an induction dose is administered to fill the initial volume of distribution, an infusion rate that matches the clearance of the drug from the central compartment will maintain a constant blood level of propofol and anesthesia. As the kinetics of propofol is linear within the range used for continuous infusions, higher or lower concentrations should be easily achieved by changing the infusion rate. ${ }^{8}$

The '10/8/6 infusion scheme', also called as the Bristol regime was first introduced by Roberts FL and colleagues in 1988, they used an induction propofol dose of $1 \mathrm{mg} \mathrm{kg}^{-1}$ and they found that there were minimal changes in the hemodynamic parameters during induction and laryngoscopy when compared to larger induction doses. ${ }^{9}$ In our study a maintenance dose of $8 / 6 / 4 \mathrm{mg} \mathrm{kg}^{-1}$ hour (GII) did not seem adequate to keep the BIS value within the range of 40 and 60 . An additional dose of propofol was required in GII $(21.6 \pm 9.9) \mathrm{mg}$ when compared to that of GI $(5.6+9.2) \mathrm{mg}$. Though the BIS value approached 60 several times, the patients were hemodynamically stable, and none reported intraoperative awareness.

A study performed by Leeuwen et al reported that a lesser number of additional bolus doses of propofol and alfentanil (propofol $20 \mathrm{mg}$ and alfentanil $1 \mathrm{mg}$ ) were required when maintenance propofol doses of $3 \mathrm{mg} \mathrm{kg}$ ${ }^{1}$ hour and $4 \mathrm{mg} \mathrm{kg}^{-1}$ hour were given as against a propofol maintenance dose of $2 \mathrm{mg} \mathrm{kg}{ }^{-1}$ hour. When clinical parameters like sweating, lacrimation, chewing on the tube, movement or sudden increase of heart rate and or systolic pressure and diastolic pressure increase of more than $15 \%$ from baseline suggests lighter plane anaesthesia, an additional dose of propofol was given. Five patients developed bradycardia and one patient developed ventilatory depression. This study indicates that additional dose of propofol cannot be administered using clinical parameters only for adequate depth of anaesthesia. ${ }^{10}$ In our study, all the patients were monitored with BIS and none developed any of these symptoms or hemodynamic instability.

The mean total dose of propofol required differed in the two groups. A mean total dose of $686.1+124.5 \mathrm{mg}$ was required in group I as against a mean total propofol dose of 562.7+94.9 mg in Group II.

Our patients were hemodynamically stable during the procedure. This was possible as titration was done using BIS values and we did not have to wait for clinical symptoms of light anaesthesia which might be accompanied by hemodynamic changes. Bajwa et al reported similar findings in a study done by them to compare propofol-fentanyl and propofol-ketamine 
anaesthesia. ${ }^{11}$ Billard and colleagues reported that increasing the propofol induction dose from $2 \mathrm{mg} \mathrm{kg}^{-1}$ to $3.5 \mathrm{mg} \mathrm{kg} \mathrm{kg}^{-1}$ did not decrease post intubation hypertension; when they increased the bolus dose of fentanyl from $2 \mu \mathrm{g} \mathrm{kg}^{-1}$ to $4 \mu \mathrm{g} \mathrm{kg}^{-1}$, there was a significant decrease in post intubation hypertension. ${ }^{12}$

None of our patients reported intraoperative awareness. For propofol-based anaesthesia, the studies have quoted $0 \%$ for minor surgical procedures in $2002,{ }^{13}$ $0.2 \%$ for general surgery in $1997,{ }^{14} 0.3 \%$ for noncardiac surgery in $1993,{ }^{15} 1.1 \%$ for non-cardiac surgery in $2008 .{ }^{3}$ As our sample size is 50, it might not have enough power to detect intraoperative awareness.

A study done by Ekman and colleagues in 2004 reported that the incidence of awareness was significantly reduced in the BIS-monitored group in comparison to a historical control group without BIS monitoring in patients who underwent noncardiac surgery. ${ }^{16}$ This study correlates with the findings in our study that BIS monitoring helps us to titrate the drugs according to the level of consciousness and prevent awareness. Our findings are further supported by a study done by Myles and co-workers in the same year that BIS monitoring is warranted in patients at high risk for awareness undergoing relaxant general anaesthesia. ${ }^{17}$ In 2008, Avidian and co-workers did a single center randomized controlled trial in 1941 patients at high risk for awareness and stated that routine BIS monitoring does not decrease the incidence of intra- operative awareness. ${ }^{18}$ Despite differing opinions, it can be stated that BIS may be effective at least at an anecdotal level, with individual accounts of monitoring alerting the anaesthetist to deficiencies in drug delivery and associated lightening of anesthesia.

\section{Conclusion}

Total intravenous anaesthesia using propofol is increasingly becoming popular due to its various advantages over conventional inhalational agents. However, as it is a short acting drug, there is concern that there may be a lighter plane of anaesthesia resulting in intraoperative awareness. However, the introduction of TIVA with newer delivery systems along with BIS monitoring have made the drug delivery flexible and titrable according to BIS values. In our study, patients were hemodynamically stable when the Bispectral index was maintained between 40 and 60 . Intraoperative awareness was not detected during this study. Therefore, the availability of Bispectral index monitoring nowadays, helps us to titrate the doses according to the level of consciousness and thereby preventing the complications like hypotension, respiratory depression with increased dosage.

\section{References}

1. Sandin Rh, Enlund G, Samuelsson P, Lennmarken C. Awareness during anesthesia: a prospective case study. Lancet. 2000;355:707-11.
2. Sebel PS, Bowdle TA, Ghoneim MM, et al. The incidence of awareness during anesthesia: a multicenter United States study. Anesth Analg. 2004;99:833.

3. Errando C L, Sigl JC, Robles M. Awareness with recall during general anaesthesia: a prospective observational evaluation of 4001 patient. Br J Anaesth. 2008;101:17885.

4. XuL, Wu As, Yue Y. The incidence of intra-operative awareness during general anesthesia in china: a multi centre observational study. Acta Anaesthesiol Scand. 2009;53:873.

Hadavi SMR, MDAllahyary E, Asadi S. (2013) Evaluation of the Adequacy of General Anesthesia in Cesarean Section by Bispectral Index. IJMS. 2013;38: 244-247.

5. Eikaas H, Raede J. Total intravenous anaesthesia techniques for ambulatory surgery. Current Opinion in Anaesthesiology. 2009;22:725-729.

6. Nadelson MR, Willingham MD, and Avidan MS. Bispectral Index Monitoring and Perioperative Outcomes: Does It Make a Difference? IARS. 2013; review course lectures.

7. Al-Rifai Z, Mulvey D. Principles of total intravenous anaesthesia: basic pharmacokinetics and model descriptions. BJA Education. 2016;16:92-97.

8. Roberts FL, Dixon J, Lewis GT, Tackley RM, PrysRoberts C. Induction and maintenance of propofol anaesthesia. A manual infusion scheme. Anaesthesia. 1988;43:14-17.

9. LeeuwenLV, Zuurmond WA, Deen L, Helmers JH. Total intravenous anaesthesia with propofol, alfentanil, and oxygen-air: three different dosage schemes. Can J Anaesth. 1990;37:282-6

10. SJ, Bajwa SK kaur J. Comparison of two drug combinations in total intravenous anesthesia: PropofolKetamine and propofol -fentanyl. Saudi J Anaesth. 2010;4:72-9.

11. Billard V, Moulla F, Bourgain J1, Megnigbeto A, Stanski DR Haemodynamic response to induction and intubation. Propofol/fentanyl interaction. Anaesthesiology. 1994;81:1384-93.

12. Enlund, M., Hassan, H.G. Intraoperative awareness: detected by the structured Brice interview? Acta Anaesthesiol Scand. 2002;46:345-49.

13. Nordstrom O, Engstrom AM, Persson S, Sandin R: Incidence of awareness in total i.v. anaesthesia based on propofol, alfentanil and neuromuscular blockade. Acta Anaesthesiol Scand. 1997;41:978-84.

14. Sandin R, Nordstrom O. Awareness during total intravenous anaesthesia. Br J Anaesth. 1993;71:782-7.

15. Lindholm ML, Lennmarken C, Sandin R. Reduction in the incidence of awareness using BIS monitoring. Acta Anaesthesiol Scand. 2004;48:20-6.

16. Myles PS, Leslie K, McNeil J, Forbes A, Chan MT. Bispectral index monitoring to prevent awareness during anaesthesia: the B-aware randomized controlled trial. Lancet. 2004;363:1757-63.

17. Avidan MS, Zhang L, Burnside BA. Anesthesia awareness and the bispectral index. $N$ Engl J Med. 2008;358:1097.

How to cite this article: Kumar BS, Pratheeba N, Remadevi R, Ravindra BR, Senthilnathan M. Bispectral index monitoring during total intravenous anaesthesia: A comparative study between two dosage regimes of propofol. Indian J Clin Anaesth. 2018;5(3):389-393. 